\title{
Comment on: Weickert MO, Pfeiffer AFH (2006) Signalling mechanisms linking hepatic glucose and lipid metabolism. Diabetologia 49:1732-1741
}

\author{
R. N. A. Black $\cdot$ P. M. Bell
}

Received: 6 October 2006 / Accepted: 26 October 2006 / Published online: 6 December 2006

(C) Springer-Verlag 2006

To the Editor: We read with interest this recent review [1] on an important aspect of glucose and lipid metabolism. It is agreed that there is evidence of metabolic dialogue involving liver, skeletal muscle and adipose tissue within a complex regulatory network. However, we question the assertion that peroxisome proliferator activator receptor $\alpha$ $(\operatorname{PPAR} \alpha)$ agonists, such as fibrates, increase insulin sensitivity. This assertion was supported by one of the studies quoted [2], which used fenofibrate, ciprofibrate and a high-affinity PPAR $\alpha$ agonist, GW9578, in a rat model in vivo. However, due to the doses and model used, the study cannot be directly extrapolated to human subjects. In contrast to the animal model evidence, in vivo studies in man show no consistent effect of PPAR $\alpha$ agonists on insulin sensitivity. Using surrogate measures, such as the oral glucose tolerance test $[3,4]$, fasting insulin $[5,6]$ and the frequently sampled intravenous glucose tolerance test $[7,8]$, variable results have been obtained. With the reference-standard method of assessment, the euglycaemichyperinsulinaemic clamp, a well-designed study in subjects with type 2 diabetes showed no effect of gemfibrozil compared with placebo [9]. In a further study comparing simvastatin and gemfibrozil in a parallel design, insulin sensitivity decreased in both groups [10]. This parallel effect may relate to lifestyle or other factors not assessed in the trial and thus ascribed to a general trial, rather than pharmacological mechanism.

R. N. A. Black $(\bowtie)$

Department of Medicine, Ulster Hospital,

Belfast, UK

e-mail: neilblack@doctors.org.uk

P. M. Bell

Regional Centre for Endocrinology and Diabetes,

Royal Victoria Hospital,

Belfast, UK
As discussed by Weickert and Pfeiffer [1], liver and skeletal muscle fat deposition both seem to cause and be affected by insulin resistance. Agents that improve fatty acid oxidation and disposal would therefore seem likely to affect insulin resistance. However plausible this assertion may be, and despite the fact that animal models suggest an effect, well-designed in vivo studies in human subjects show no significant improvement in insulin sensitivity using PPAR $\alpha$ agonists at doses which are currently recommended for therapy in man $[9,10]$. As recognised by Guerre-Millo et al. [2], fibrates are low-affinity ligands for PPAR $\alpha$, and agents with higher affinity may be required to elicit a significant effect. Recent reviews such as the detailed, considered article in question [1] should recognise that this effect is not seen with these agents in man.

\section{References}

1. Weickert MO, Pfeiffer AFH (2006) Signalling mechanisms linking hepatic glucose and lipid metabolism. Diabetologia 49:1732-1741

2. Guerre-Millo M, Gervois P, Raspé E et al (2000) Peroxisomeproliferator-activated receptor alpha receptors improve insulin sensitivity and improve adiposity. J Biol Chem 275:16638-16642

3. Hernandez-Mijares A, Lluch I, Vizcarra E et al (2000) Ciprofibrate effects on carbohydrate and lipid metabolism in type 2 diabetes mellitus subjects. NMCD, Nutr Metab Cardiovasc Dis $10: 1-6$

4. Kobayashi M, Shigeta Y, Hirata Y et al (1988) Improvement of glucose tolerance in NIDDM by clofibrate. Randomized doubleblind study. Diabetes Care 11:495-499

5. Cavallero E, Dachet C, Assadolahi F et al (2003) Micronized fenofibrate normalizes the enhanced lipidemic response to a fat load in patients with type 2 diabetes and optimal glucose control. Atherosclerosis 166:151-161

6. Elkeles RS, Diamond JR, Anyaoku V et al (1999) Long term improvement in dyslipidaemia in type 2 diabetes with bezafibrate 
is not related to changes in insulin resistance. Atherosclerosis 146:195-196

7. Avogaro A, Miola M, Favaro A et al (2001) Gemfibrozil improves insulin sensitivity and flow-mediated vasodilatation in type 2 diabetic patients. Eur J Clin Investig 31:603-609

8. Stewart MW, Dyer RG, Alberti KGMM et al (1995) The effects of lipid lowering drugs on metabolic control and lipoprotein composition in type 2 diabetic patients with mild hyperlipidaemia. Diabet Med 12:250-257
9. Vuorinen-Markkola H, Yki-Yarvinen H, Taskinen M-R (1993) Lowering of triglycerides by gemfibrozil affects neither the glucoregulatory nor antilipolytic effect of insulin in type 2 (non-insulin dependent) diabetic patients. Diabetologia 36:161169

10. Öhrvall M, Lithell H, Johansson J et al (1995) A comparison between the effects of gemfibrozil and simvastatin on insulin sensitivity in patients with non-insulin-dependent diabetes mellitus and hyperlipoproteinemia. Metabolism 44:212-217 